\title{
Refractory Cytomegalovirus Infection
}

National Cancer Institute

\section{Source}

National Cancer Institute. Refractory Cytomegalovirus Infection. NCI Thesaurus. Code C162748.

A cytomegalovirus infection that is resistant to treatment. 